\title{
Cocaine- and amphetamine-regulated transcript (CART) peptide in the nerve fibres of the porcine gallbladder wall under physiological conditions and after Salmonella Enteritidis lipopolysaccharides administration
}

\author{
A. Mikolajczyk ${ }^{1 *}$, K. Makowska ${ }^{2 *}$ \\ ${ }^{1}$ Department of Public Health, Epidemiology and Microbiology, Faculty of Medical Sciences, University of Warmia \\ and Mazury, Olsztyn, Poland \\ 2Department of Clinical Physiology, Faculty of Veterinary Medicine, University of Warmia and Mazury, Olsztyn, Poland \\ [Received: 8 February 2017; Accepted: 17 March 2017]
}

Background: Cocaine- and amphetamine-regulated transcript (CART) peptide is the substance distributed in various parts of the nervous system. The majority of previous studies described this substance in the brain, where it takes part in regulatory processes connected with the food intake. CART is also present in the peripheral nervous system, especially in the enteric neurons and nerves located in the wall of the stomach and intestine, but many aspects of distribution and functions of this peptide in the digestive organs remain unknown. The aim of the present study was to investigate the changes of CART-positive nerves in the porcine gallbladder after administration of low-dose Salmonella Enteritidis lipopolysaccharide (LPS) using the single immunofluorescence technique.

Materials and methods: Seven days after the injection of $5 \mu \mathrm{g} / \mathrm{kg}$ b.w. LPS S. Enteritidis the gallibladders were collected. CART-positive nerves were studied with standard single immunofluorescence method and counted per observation field $\left(0.1 \mathrm{~m}^{2}\right)$.

Results: In control animals the average number of CART-positive nerves per observation field $\left(0.1 \mathrm{~mm}^{2}\right)$ amounted to $5.38 \pm 0.32,11.11 \pm 1.56$ and $2.97 \pm$ \pm 0.24 in gallbladder neck, body and fundus, respectively. LPS administration caused the increase in the number of CART-positive fibres in all parts of gallibladder, and these values amounted to $12.74 \pm 0.51,19.75 \pm 0.19$ and $5.1 \pm 0.05$ in the gallbladder neck, body and fundus, respectively.

Conclusions: The obtained results suggest that CART is involved in the neuronal regulatory processes in the porcine gallbladder under physiological conditions, but also during pathological processes, but exact functions of this peptide in this organ remain unexplained and require the further investigation. (Folia Morphol 2017; 76, 4: 596-602)

Key words: lipopolysaccharide (LPS), Salmonella Enteritidis, immunofluorescence, nerves, cocaine- and amphetamine-regulated transcript (CART) 


\section{INTRODUCTION}

Cocaine- and amphetamine-regulated transcript (CART) peptide is the substance widely distributed in the living organism, both in the nervous system and endocrine cells [25]. It has been described for the first time in the ovine hypothalamus in 1981 by Spiess et al. [35]. CART, whose name derives from the increase in its level after administration of cocaine and amphetamine in rat striatum [7], occurs in various forms, of which CART 55-102 and CART 62-102 are the most important in terms of biological activity $[23,25]$.

First of all CART has been described in the central nervous system, where it is localised among others in the hypothalamus, nucleus of the solitary tract, nucleus accumbens, thalamic relay nuclei, olfactory bulb and amygdala [7, 22]. It is well known, that this peptide may be involved in a broad spectrum of functions within the central nervous system. CART is mainly known as a factor which participates in the feeding behaviour as an important inhibitor of appetite [37], but it also takes part in the autonomic regulation, fluid balance, processes connected with actions of anxiety and reward system, sensory stimuli conduction, as well as stress and immunological reactions $[1,18,25,38]$.

Contrary to the brain, the knowledge concerning the distribution and functions of CART in the peripheral nervous system is rather scanty. Till now, CART has been described in neuronal structures of spinal preganglionic nuclei, pancreas and adrenal medulla $[8,17,25,41]$, but particularly high number of neurons and nerve fibres immunoreactive to CART has been noted in the enteric nervous system located in the wall of the gastrointestinal tract $[3,14,25,42]$. In spite of the fact that CART is relatively prevalent in the wall of stomach and intestine, its functions within the gastrointestinal tract are not fully explained. It is assumed that this peptide may participate in regulatory processes connected with intestinal motility, but mechanisms of these actions still remain unknown $[34,36]$. Moreover, it is known that expression of CART in the enteric nervous structures may change under the influence of various pathological factors, which suggests the participation of this peptide in adaptive and/or neuroprotective processes within enteric neurons during intestinal and extra-intestinal diseases and intoxications $[12,15,16,26]$.

It should be pointed out that, contrary to the stomach and intestine, information about distribution of CART in nervous structures within the gallbladder wall is very scanty, because only one previous study [10] described this substance in intramural neuronal structures of the gallbladder of guinea pig.

Therefore, the aim of the present investigation was to investigate the distribution of CART in nerve fibres located in the wall of different part of porcine gallbladder both under physiological conditions and after administration of lipopolysaccharide (LPS) from Salmonella Enteritidis. Lipopolysaccharides - the common component of Gram-negative bacteria cell wall are known as the factor that causes a wide range of pathological reactions including endotoxin shock, various tissue injury, disturbances in immunological processes and lethality $[4,29]$. The gallbladder may also undergo changes under the influence of LPS. Previous studies described, among others, LPS-induced cholecystitis and fluctuations in mucin secretion by gallbladder epithelial cells $[5,20]$, but the changes in the innervation of this organ after LPS administration has not been investigated at all. Moreover, the majority of previous studies concerned the high doses of LPS $[11,19,20]$, while this study was performed on "low single dose", which can simulate the asymptomatic carrier state of Salmonella spp.

On the other hand, the pig, species used during the present experiment, seems to be an optimal experimental animal due to relatively well known anatomical, physiological and enzymatic similarities between human and porcine organisms [39]. So the results obtained during this study, may be an animal model of the influence of LPS on human gallbladder.

\section{MATERIALS AND METHODS}

The investigation was performed on 10 immature sows (at the age of 8-9 weeks, $16-18 \mathrm{~kg}$ body weight) Piétrain $\times$ Duroc breed, which during experimental procedures were kept in typical laboratory condition and nourished using standard feed for pigs of this age group. Animals were clinically healthy, and in all pigs faecal analysis excluded asymptomatic carrier state of Salmonella sp. After 2-week adaptive period animals were randomly divided into two groups (5 pigs in each group): control group (C group) and experimental (LPS group). All animals were premedicated, according to the method previously described by Mikolajczyk [28], with intramuscular injection of atropine (Atropinum Sulfuricum, Polfa Warszawa S.A., Poland, $0.035 \mathrm{mg} / \mathrm{kg}$ b.w.), ketamine (Bioketan, Vetoquinol Biowet Sp. z o.o., Poland \& Vetoquinol 
S.A., France, $7.0 \mathrm{mg} / \mathrm{kg}$ b.w.) and medetomidine (Cepetor, CP-PharmaHandelsges $\mathrm{mbH}$, Germany, $0.063 \mathrm{mg} / \mathrm{kg}$ b.w.).

Then, in experimental group LPS from Salmonella enterica serotype Enteritidis (catalogue no. L7770 Sigma, Aldrich, Germany) was given intravenously into the marginal ear vein at dose $5 \mu \mathrm{g} / \mathrm{kg}$ b.w. (in $10 \mathrm{~mL}$ saline solution), described previously as a "low single dose", which in experimental conditions may simulate the asymptomatic carrier state of Salmonella spp. [40]. The control animals received intravenously $10 \mathrm{~mL}$ saline solution without LPS.

All experimental procedures were performed in agreement with the instructions of Local Ethical Committee for Animal Experimentation in Olsztyn, Poland (decision no. 73/2015 from 29th September 2015).

After 7 days - the period which in the light of the previous studies is sufficient for the emergence of changes in the nervous system after LPS administration [31, 32], all pigs were again premedicated (in the described above manner) and after $15 \mathrm{~min}$ were subjected to general anaesthesia using propofol (Scanofol, NORBROOK, Northern Ireland, IRL.PN, $4.5 \mathrm{mg} / \mathrm{kg}$ b.w. given intravenously) and then euthanised with pentobarbital (Morbital, Biowet Puławy Sp. z o.o, Poland, 60-70 mg/kg b.w., given intravenously).

Immediately after euthanasia gallbladders were collected, fixed in a solution of $4 \%$ buffered paraformaldehyde ( $\mathrm{pH} \mathrm{7.4)} \mathrm{for} 30 \mathrm{~min}$ and rinds in phosphate buffer $\left(0.1 \mathrm{M}, \mathrm{pH} 7.4\right.$, at $\left.4^{\circ} \mathrm{C}\right)$ for 3 days (with daily exchange of buffer). Then tissues are put into $18 \%$ phosphate-buffered sucrose and storage at $4^{\circ} \mathrm{C}$ for at least 2 weeks. After this period the particular parts of gallbladders (neck, body and fundus) were frozen at $-22^{\circ} \mathrm{C}$, cut perpendicular to the lumen into $14-\mu \mathrm{m}$-thick sections using microtome (Microm, HM 525, Walldorf, Germany), fixed on glass slides and subjected to single-labelling immunofluorescence technique described previously by Gonkowski et al. [13]. Sections of the particular parts of gallbladders were dried for $45 \mathrm{~min}$ at room temperature (RT) and incubated (1 h, RT) with blocking solution (10\% goat serum, $0.1 \%$ bovine serum albumin [BSA], $0.01 \%$ $\mathrm{NaN}_{3}$, Triton X-100, thimerosal in phosphate buffered saline [PBS]). Then, samples were incubated (overnight; RT, in a humid chamber) with rabbit antiCART IgG (Phoenix Pharmaceuticals, INC, Belmont, CA, USA, catalogue no. 1-003-61, working dilution $1: 8000)$. The next day, complexes of mentioned above antibodies and appropriate antigens were visualised
Table 1. The number of nerve fibres immunoreactive to cocaine- and amphetamine-regulated transcript (CART) peptide per observation field $\left(0.1 \mathrm{~mm}^{2}\right)$ in the neck, fundus and body of porcine gallbladder under physiological conditions ( $C$ group) and after administration of lipopolysaccharides (LPS group); mean \pm standard error of mean (SEM)

\begin{tabular}{lcc}
\hline Part of gallbladder & C group & LPS group \\
\hline Neck & $5.38 \pm 0.32^{*}$ & $12.74 \pm 0.51^{*}$ \\
Body & $11.11 \pm 1.56^{*}$ & $19.75 \pm 0.19^{*}$ \\
Fundus & $2.97 \pm 0.24^{*}$ & $5.1 \pm 0.05^{*}$ \\
\hline
\end{tabular}

Statistically significant differences $(p \leq 0.05)$ between $C$ and LPS groups in the particular parts of the gallbladder are indicated with asterisk $\left(^{*}\right)$.

by incubation ( $1 \mathrm{~h}, \mathrm{RT}$ ) with secondary antibody Alexa Fluor 546 donkey anti-rabbit IgG (Invitrogen, Carlsbad, CA, USA, working dilution 1:1000). Each step of immunofluorescence technique was followed by rinsing the sections with PBS $(3 \times 10 \mathrm{~min}, \mathrm{pH} 7.4)$.

To denotation of the labelling specificity standard control procedures, including pre-absorption of anti-CART IgG with appropriate antigen, as well as "omission" and "replacement" tests were performed and these procedures completely eliminated specific stainings.

The evaluation of the density of CART-positive nerves in the wall of particular parts of gallbladder (including neck, body and fundus) was performed by the counting of these fibres per microscopic observation field $\left(0.1 \mathrm{~mm}^{2}\right)$. The number of nerve fibres were denoted in 4 fragments of the particular parts of gallbladder per each pig (in 5 field per section) and obtained data were pooled and presented as mean \pm standard error of mean (SEM). Statistical analysis was made with ANOVA-test (Statistica 9.1, StatSoft, Inc.) and differences were considered statistically significant at $p \leq 0.05$.

\section{RESULTS}

During the present investigation CART-positive nerve fibres were noted in the wall of all parts of the gallbladder studied, both under physiological conditions and after LPS administration (Table 1, Fig. 1), and the density of them clearly depended on the gallbladder fragment. All CART-like immunoreactive (LI) nerves studied during the present experiment were situated within the muscular layer.

In control animals the most numerous nerves immunoreactive to CART were localised within the body of gallbladder, where the number of them averagely amounted to $11.11 \pm 1.56$ CART-LI nerves per obser- 

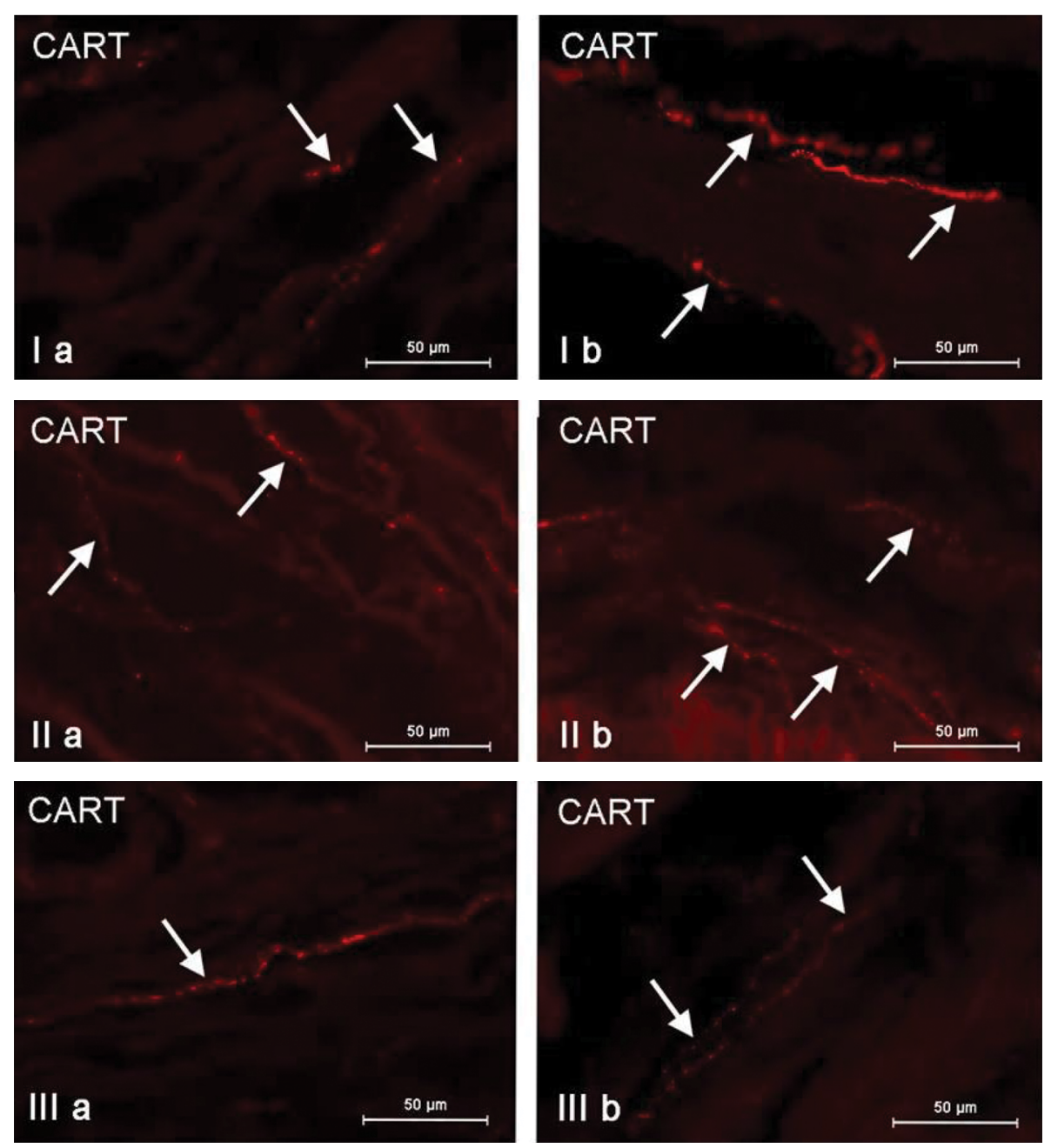

Figure 1. Nerve fibres immunoreactive to cocaine and amphetamine regulatory (CART) peptide in the neck (I), body (II) and fundus (III) of the porcine gallbladder under physiological conditions (a) and after lipopolysaccharides administration (b); CART-like immunoreactive nerves are indicated with arrows.

vation field (Fig. 1, lla). Significantly smaller number of fibres was observed in the neck and fundus (Fig. 1, la) of the gallbladder (Fig. 1, Illa), where these values achieved $5.38 \pm 0.32$ and $2.97 \pm 0.24$, respectively (Table 1 ).

LPS S. Enteritidis administration caused the increase in the number of CART-positive nerves in all parts of the gallbladder (Fig. 1, I-IIlb), but the intensity of observed changes was varied (Table 1). The most visible fluctuation in the number of CART-LI fibres was noted in the body o gallbladder (the increase by above 8.5 percentage points [pp]) (Fig. 1, IIb). A slightly lower changes were observed in the gallbladder neck, where LPS-induced increase in the CART-positive fibres density amounted to above $7 \mathrm{pp}$ (Table 1, Fig. 1, Ib). The less visible changes were studied within the fundus of gallbladder (Fig. 1, IIlb). In this fragment the average number of CART-positive nerves has increased from $2.97 \pm 0.24$ to $5.1 \pm 0.05$ per observation field (above $4 \mathrm{pp}$ ). Differences in the number of CART-LI nerves located in all parts of gallbladder between control animals and pigs after LPS administration were statistically significant $(p \leq 0.05)$.

Moreover, LPS changed not only the number, but also morphology of CART-positive fibres in the wall of gallbladder. Namely, in control animals two types of nerves immunoreactive to CART were noted. The first (more numerous) group of them was composed of rather thin and delicate nerves (Fig. 1, la, Ila), and the second group of rare thick fibres (Fig. 1, IIla). In pigs after LPS administration the majority of CART-positive fibres were thick and formed bundles with good visible varicosities (Fig. 1, lb).

\section{DISCUSSION}

The results obtained during the present study are generally in agreement with previous observations 
concerning investigations on the gallbladder and gastrointestinal tract. Till now, the sole animal species, in which CART-positive neuronal structures have been noted in nervous structures of gallbladder wall, is the guinea pig, where this substance is present in relatively numerous varicose fibres and only single intramural neurons [10]. Contrary to the gallbladder, the knowledge concerning the distribution of CART in nervous structures of the gastrointestinal tract is significantly extensive. Namely, this substance has been studied in the different part of the gastrointestinal tract in a wide range of mammals' species, including human, both in enteric neurons and nerve fibres, especially located in the muscular layer [25]. So far, the exact function of CART in the neuronal structures within the stomach and intestine are not completely explained. It is known that this peptide may influence the gastric acid secretion and intestinal motility $[34,36]$. These actions are probably regulated via central nervous system, because direct addition of CART peptide into intestinal cell culture doesn't cause mentioned above effects [9]. The main difficulty in the exact elucidation of CART activity is that till now the receptors for CART has not been discovered.

The functions of CART in the innervation of the gallbladder are completely unknown, but probably similar to those, which this peptide plays in the gastrointestinal tract, namely the participation in the regulation of muscular contractility and excretive activity of the mucosal layer. Moreover, it cannot be excluded that CART in neuronal structures of the gallbladder may act (like in the central nervous system) as an endogenous antioxidant and exhibits neuroprotective and neurotrophic effects, especially during neuronal cells injury $[2,24,27,43]$. It is all the more probable that relatively large number of previous studies showed the changes in the number of CART-positive enteric nervous during a wide range of intestinal and extra-intestinal processes [15, 21, 33], and such fluctuations were also noted during the present study.

It should be pointed out that the exact mechanisms of observed changes are difficult to explain, especially due to the fact that the majority of previous investigations described the influence of high doses of LPS. First of all, the fluctuation in CART-like immunoreactivity may be connected with relatively well-known pro-inflammatory effects of LPS [11]. This LPS activity has been also described within the enteric nervous system, where bacterial endotoxins caused the significant increase in the synthesis of the major pro-inflammatory cytokine - tumour necrosis factor-alpha [6]. Probably these mechanisms take place even in the case of low doses of LPS using during the present study. On the other hand, changes observed in this investigation can be connected with other actions of LPS, such as the blockade of synaptic transmissions, neurodegenerative activity and/or the influence on sensory stimuli conduction $[6,11$, 31]. Direct reasons of observed changes are also not clear. They may be the result of changes during various stages of protein synthesis, including transcription, translation or post-translational modification, in which active forms of CART arise from proCART polypeptide [23].

\section{CONCLUSIONS}

To sum up, the results obtained during the present investigations not only show that CART is present in the nervous structures localised in the wall of porcine gallbladder, but also exhibit the changes in immunoreactivity to this peptide under the influence of low doses of LPS. These observations suggest the participation of CART in regulation of gallbladder functions both in physiological conditions and under pathological factors. Nonetheless, these functions still remain unknown and the explanation the exact roles of CART in the gallbladder requires the further study, in which the denotation of specific receptors for this peptide seems to be a key problem.

\section{Acknowledgements}

The study was conducted as a part of research project no. 25.610.001-300 financed by University of Warmia and Mazury, M. Oczapowskiego 2, PL 10-957 Olsztyn, Poland, NIP 7393033097.

\section{REFERENCES}

1. Balkan B, Keser A, Gozen O, et al. Forced swim stress elicits region-specific changes in CART expression in the stress axis and stress regulatory brain areas. Brain Res. 2012; 1432: 56-65, doi: 10.1016/j.brainres.2011.11.006, indexed in Pubmed: 22137563.

2. Bharne AP, Upadhya MA, Shelkar GP, et al. Neuroprotective effect of cocaine- and amphetamine-regulated transcript peptide in spinal cord injury in mice. Neuropharmacology. 2013; 67: 126-135, doi: 10.1016/j.neuropharm.2012.10.028, indexed in Pubmed: 23151374.

3. Bulc M, Gonkowski S, Landowski P, et al. Immunohistochemical distribution of cocaine and amphetamine regulatory peptide-like immunoreactive (CART-LI) nerve fibers in 
the circular muscle layer and their relationship to other peptides in the human caecum. Acta Histochem. 2014; 116(6): 1029-1036, doi: 10.1016/j.acthis.2014.04.009, indexed in Pubmed: 24907030.

4. Chen K, Geng S, Yuan R, et al. Super-low dose endotoxin pre-conditioning exacerbates sepsis mortality. EBioMedicine. 2015; 2(4): 324-333, doi: 10.1016/j.ebiom.2015.03.001, indexed in Pubmed: 26029736.

5. Choi J, Klinkspoor JH, Yoshida T, et al. Lipopolysaccharide from Escherichia coli stimulates mucin secretion by cultured dog gallbladder epithelial cells. Hepatology. 1999; 29(5): 1352-1357, doi: 10.1002/hep.510290515, indexed in Pubmed: 10216115.

6. Coquenlorge S, Duchalais E, Chevalier J, et al. Modulation of lipopolysaccharide-induced neuronal response by activation of the enteric nervous system. J Neuroinflammation. 2014; 11: 202, doi: 10.1186/s12974-014-0202-7, indexed in Pubmed: 25497784.

7. Douglass J, McKinzie AA, Couceyro P. PCR differential display identifies a rat brain mRNA that is transcriptionally regulated by cocaine and amphetamine. J Neurosci. 1995; 15(3 Pt 2): 2471-2481, indexed in Pubmed: 7891182.

8. Dun SL, Chianca DA, Dun NJ, et al. Differential expression of cocaine- and amphetamine-regulated transcriptimmunoreactivity in the rat spinal preganglionic nuclei. Neurosci Lett. 2000; 294(3): 143-146, doi: 10.1016/ s0304-3940(00)01575-5, indexed in Pubmed: 11072135.

9. Ekblad E, Kuhar M, Wierup N, et al. Cocaine- and amphetamine-regulated transcript: distribution and function in rat gastrointestinal tract. Neurogastroenterol Motil. 2003; 15(5): 545-557, doi: 10.1046/j.1365-2982.2003.00437.x, indexed in Pubmed: 14507354.

10. Ellis LM, Mawe GM. Distribution and chemical coding of cocaine- and amphetamine-regulated transcript peptide (CART)-immunoreactive neurons in the guinea pig bowel. Cell Tissue Res. 2003; 312(3): 265-274, doi: 10.1007/ s00441-002-0678-9, indexed in Pubmed: 12768408.

11. Gnauck A, Lentle RG, Kruger MC. The characteristics and function of bacterial lipopolysaccharides and their endotoxic potential in humans. Int Rev Immunol. 2016; 35(3): 189-218, doi: 10.3109/08830185.2015.1087518, indexed in Pubmed: 26606737.

12. Gonkowski $S$, Burliński $P$, Szwajca $P$, et al. Changes in cocaine- and amphetamine-regulated transcript-like immunoreactive (CART-LI) nerve structures of the porcine descending colon during proliferative enteropathy. Bull Vet Inst Pulawy. 2012; 56(2), doi: 10.2478/v10213-012-0036-y.

13. Gonkowski S, Kaminska B, Burlinski $P$, et al. The influence of drug-resistant ulcerative colitis on the number of cocaine- and amphetamine-regulated transcript peptide-like immunoreactive (CART-LI) mucosal nerve fibres of the descending colon in children. Prz Gastroenterol. 2009; 4(3): 147-151.

14. Gonkowski S, Kamińska B, Landowski P, et al. Immunohistochemical distribution of cocaine- and amphetamineregulated transcript peptide - like immunoreactive (CARTLI) nerve fibers and various degree of co-localization with other neuronal factors in the circular muscle layer of human descending colon. Histol Histopathol. 2013; 28(7): 851-858, doi: 10.14670/HH-28.851, indexed in Pubmed: 23277430.
15. Gonkowski S, Obremski K, Calka J. The influence of low doses of zearalenone on distribution of selected active substances in nerve fibers within the circular muscle layer of porcine ileum. J Mol Neurosci. 2015; 56(4): 878-886, doi: 10.1007/s12031-015-0537-2, indexed in Pubmed: 25772391.

16. Gunnarsdóttir A, Wierup N, Larsson LT, et al. CARTpeptide immunoreactivity in enteric nerves in patients with Hirschsprung's disease. Eur J Pediatr Surg. 2007; 17(3): 184-189, doi: 10.1055/s-2007-965164, indexed in Pubmed: 17638157.

17. Janiuk I, Młynek K. Immunodetection of cocaine- and amphetamine-regulated transcript in bovine pancreas. Acta Histochem. 2015; 117(6): 545-550, doi: 10.1016/j. acthis.2015.04.004, indexed in Pubmed: 25953739.

18. Jaworski JN, Jones DC. The role of CART in the reward/reinforcing properties of psychostimulants. Peptides. 2006; 27(8): 1993-2004, doi: 10.1016/j.peptides.2006.03.034, indexed in Pubmed: 16766084.

19. Kaminski DL, Feinstein WK, Deshpande YG. The production of experimental cholecystitis by endotoxin. Prostaglandins. 1994; 47(3): 233-245, indexed in Pubmed: 8016392.

20. Kaminski DL, Amir G, Deshpande YG, et al. Studies on the etiology of acute acalculous cholecystitis: the effect of lipopolysaccharide on human gallbladder mucosal cells. Prostaglandins. 1994; 47(4): 319-330, indexed in Pubmed: 8041874.

21. Kasacka I, Piotrowska Z. Evaluation of density and distribution of CART-immunoreactive structures in gastrointestinal tract of hypertensive rats. Biofactors. 2012; 38(6): 407-415, doi: 10.1002/biof.1037, indexed in Pubmed: 22887004.

22. Koylu EO, Couceyro PR, Lambert PD, et al. Immunohistochemical localization of novel CART peptides in rat hypothalamus, pituitary and adrenal gland. J Neuroendocrinol. 1997; 9(11): 823-833, doi: 10.1046/j.13652826.1997.00651.x, indexed in Pubmed: 9419833.

23. Kuhar MJ, Yoho LL. CART peptide analysis by Western blotting. Synapse. 1999; 33(3): 163-171, doi: 10.1002/(SICI)1098-2396(19990901)33:3<163::AIDSYN1 > 3.0.CO;2-T, indexed in Pubmed: 10420164.

24. Luo Yu, Shen H, Liu HS, et al. CART peptide induces neuroregeneration in stroke rats. J Cereb Blood Flow Metab. 2013; 33(2): 300-310, doi: 10.1038/jcbfm.2012.172, indexed in Pubmed: 23211962.

25. Makowska K, Gonkowski S. Cocaine- and amphetamineregulated transcript (CART) peptide in mammals gastrointestinal system - a review. Ann Anim Sci. 2017; 17(1), doi: 10.1515/aoas-2016-0014.

26. Makowska K, Gonkowski S, Zielonka L, et al. T2 toxin-induced changes in cocaine- and amphetamineregulated transcript (cart)-like immunoreactivity in the enteric nervous system within selected fragments of the porcine digestive tract. Neurotox Res. 2017; 31(1): 136-147, doi: 10.1007/s12640-016-9675-8, indexed in Pubmed: 27738989.

27. Mao $P$, Meshul CK, Thuillier $P$, et al. CART peptide is a potential endogenous antioxidant and preferentially localized in mitochondria. PLoS One. 2012; 7(1): e29343, doi: 10.1371/journal.pone.0029343, indexed in Pubmed: 22235287. 
28. Mikolajczyk A. Safe and effective anaesthesiological protocols in domestic pigs. Ann Warsaw Univ Life Sci - SGGW Anim Sci. 2016; 55(2): 219-227.

29. Norimatsu M, Ono T, Aoki A, et al. Lipopolysaccharide-induced apoptosis in swine lymphocytes in vivo. Infect Immun. 1995; 63(3): 1122-1126, indexed in Pubmed: 7868236.

30. Prystowsky JB, Rege RV. Neurogenic inflammation in cholecystitis. Dig Dis Sci. 1997; 42(7): 1489-1494, indexed in Pubmed: 9246052.

31. Qin L, Wu X, Block ML, et al. Systemic LPS causes chronic neuroinflammation and progressive neurodegeneration. Glia. 2007; 55(5): 453-462, doi:10.1002/glia.20467, indexed in Pubmed: 17203472.

32. Rivera-Aguilar V, Querejeta E, Jarillo-Luna RA, et al. Role of the striatum in the humoral immune response to thymus-independent and thymus-dependent antigens in rats. Immunol Lett. 2008; 120(1-2): 20-28, doi: 10.1016/j. imlet.2008.06.006, indexed in Pubmed: 18639583.

33. Rychlik A, Gonkowski S, Nowicki M, et al. Cocaine- and amphetamine-regulated transcript immunoreactive nerve fibres in the mucosal layer of the canine gastrointestinal tract under physiological conditions and in inflammatory bowel disease. Vet Med-Czech. 2015; 60(7): 361-367, doi: 10.17221/8383-vetmed.

34. Smedh U, Moran T. Separable mechanisms for dorsal hindbrain CART peptide to inhibit gastric emptying and food intake. Am J Physiol Regul Integr Comp Physiol. 2003; 284(6): R1418-R1426, doi: 10.1152/ajpregu.00665.2002.

35. Spiess J, Villarreal J, Vale W. Isolation and sequence analysis of a somatostatin-like polypeptide from ovine hypothalamus. Biochemistry. 1981; 20(7): 1982-1988, indexed in Pubmed: 7225368.

36. Tebbe JJ, Ortmann E, Schumacher K, et al. Cocaine- and amphetamine-regulated transcript stimulates colonic motility via central CRF receptor activation and peripheral cholinergic pathways in fed, conscious rats. Neurogastro- enterol Motil. 2004; 16(4): 489-496, doi: 10.1111/j.13652982.2004.00561.x, indexed in Pubmed: 15306004.

37. Thim $L$, Kristensen $P$, Larsen $P$, et al. CART, a new anorectic peptide. nt J Biochem Cell Biol. 1998; 30(12): 1281-1284, doi: 10.1016/s1357-2725(98)00110-1.

38. Vicentic A, Jones DC. The CART (cocaine- and amphetamine-regulated transcript) system in appetite and drug addiction. J Pharmacol Exp Ther. 2007; 320(2): 499-506, doi: 10.1124/jpet.105.091512, indexed in Pubmed: 16840648.

39. Verma N, Rettenmeier AW, Schmitz-Spanke S. Recent advances in the use of Sus scrofa (pig) as a model system for proteomic studies. Proteomics. 2011; 11(4): 776-793, doi: 10.1002/pmic.201000320, indexed in Pubmed: 21229584.

40. Webel DM, Finck BN, Baker DH, et al. Time course of increased plasma cytokines, cortisol, and urea nitrogen in pigs following intraperitoneal injection of lipopolysaccharide. J Anim Sci. 1997; 75(6): 1514-1520, indexed in Pubmed: 9250511.

41. Wierup N, Gunnarsdóttir A, Ekblad E, et al. Characte-risation of CART-containing neurons and cells in the porcine pancreas, gastro-intestinal tract, adrenal and thyroid glands. BMC Neurosci. 2007; 8: 51, doi: 10.1186/14712202-8-51, indexed in Pubmed: 17625001.

42. Wojtkiewicz J, Gonkowski S, Bladowski M, et al. Characterisation of cocaine- and amphetamine-regulated transcript-like immunoreactive (CART-LI) enteric neurons in the porcine small intestine. Acta Vet Hung. 2012; 60(3): 371-381, doi: 10.1556/AVet.2012.032, indexed in Pubmed: 22903082.

43. Wu B, Hu S, Yang M, et al. CART peptide promotes the survival of hippocampal neurons by upregulating brain-derived neurotrophic factor. Biochem Biophys Res Commun. 2006; 347(3): 656-661, doi: 10.1016/j.bbrc.2006.06.117, indexed in Pubmed: 16842741. 